\title{
STATISTICS OF ACUTE PARAPLEGIA AND TETRAPLEGIA ON A NATIONAL SCALE
}

\author{
SWITZERLAND $1960-67$ \\ R. GeHrig, lic.oec. (St. Gallen), and L. S. Michaelis, M.D. ${ }^{1}$ \\ From the Swiss Paraplegic Centre in Basle
}

To have reliable data as to the incidence of acute, traumatic or non-traumatic paraplegia and tetraplegia in peacetime is of real interest to all those charged with the provision of suitable facilities for the treatment and rehabilitation of this group of the disabled.

Switzerland, a highly organised small country, appeared particularly suited for an attempt to test two assumptions:

I. That the number of cases of traumatic paraplegia and tetraplegia has been increasing during recent years.

2. That one must count on Io new patients with traumatic paraplegia or tetraplegia among a million members of the population per annum.

With the help of Professor Tanner, chief medical adviser to the Schweizerische Rückversicherungs-Gesellschaft (Swiss Reinsurance Company) of Zürich, a statistical survey of the whole of Switzerland was organised. One of us (R. G.) was appointed to carry out the field work.

Procedure. A letter was written to all-some 240-hospitals in Switzerland which asked whether, during the years 1960-67, they had at any time admitted patients suffering from paraplegia or tetraplegia. The authorities of 65 hospitals replied that they had.

A detailed three-page questionnaire was first prepared by the insurance company and then completed by adding questions of special medical interest in collaboration with doctors working in this field.

R. G. visited every one of the 65 hospitals on appointment and completed the forms from the notes and other data provided. Patients were carefully identified so as to prevent double-counting in cases where they had attended various hospitals at different times. Throughout his travels the authors conferred frequently in order to clear up points of uncertainty when they arose.

Definition of Acute Paraplegia and Tetraplegia. The definition of acute traumatic cases presented no problems. Acute non-traumatic paraplegia (due to transverse myelitis, epidural abscess or vascular incidents) was more difficult to define. Tumours of the cord or spine and congenital paraplegia due to myelocele were not included, nor were cases of disseminated sclerosis and Friedreich's ataxia.

Collaboration with the authorities of the hospitals, medical and secretarial, was-with a few exceptions-very satisfactory. The following table records traumatic cases only. About is to 18 per cent. per annum have to be added to

1 Present address: c/o Stoke Mandeville Hospital, Aylesbury, Bucks, England. 
the annual totals to account for acute paraplegia and tetraplegia due to causes other than trauma.

\section{TABLE}

Traumatic Paraplegia and Tetraplegia in Switzerland, 1960-67

I. New Lesions (p.a.)

\begin{tabular}{ll} 
I960 & 56 \\
I96I & 65 \\
I962 & 75 \\
I963 & 80 \\
I964 & 73 \\
I965 & 64 \\
I966 & 8 I \\
I967 & 80 (estim.) \\
\hline Total & 584
\end{tabular}

Average increase p.a. $4 \%$

2. Age-groups (years)

$\begin{array}{cr}\text { I-9 } & 3 \% \\ \text { IO-I9 } & 16 \% \\ 20-29 & 29 \% \\ 30-39 & 14 \% \\ 40-49 & 12 \%\end{array}$

Total population

I960 M 5,430,000

Average increase p.a. $\quad 2 \cdot 3 \%$

3. Sex Distribution

Men $79 \%$, Women $16 \%$, Children $5 \%$ (under 14 ).

\section{Occupation}

Workmen and apprentices (industrial and building) . . . . . . . . $48 \%$

Employees (office, etc.), housewives, schoolchildren - . . . . . . . $\quad .35 \%$

Farmers and farm-labourers . . . . . . . . . . . . . $\quad . \quad 12 \%$

Employers, professional people $\quad . \quad$. $\quad . \quad . \quad . \quad . \quad . \quad . \quad . \quad . \quad 5 \%$

\section{Causes of Accidents}

$$
\begin{aligned}
& \text { Road-traffic . . . } 36 \% \\
& \text { At work . . . } 35 \% \\
& \text { Home and sport . . . } 29 \%
\end{aligned}
$$

Of the last $29 \%$, one-third was due to attempted suicide, one-third to diving, the remainder to mixed causes. A national sport ('Swinging', a form of wrestling), accounted for five tetraplegics in seven years.

6. Of the total, two-thirds were paraplegics, one-third tetraplegics.

7. No reliable data exist from which the relative numbers of complete and incomplete lesions could be assessed. If some 70 patients examined as in-patients or out-patients so far at the new Centre in Basle are any guide, about half of the lesions are incomplete, two-thirds of the cervical, one-third of the dorsal and almost all of the lumbar lesions. 
Further statistical material of special medical interest (methods of initial treatment, frequency of complications, time in hospital, return to work, etc.) was collected at the same time but does not concern us here.

Conclusions. Analysis of the figures obtained shows an annual increase in population of $2 \cdot 3$ per cent., of traumatic paraplegia and tetraplegia of 4 per cent. The absolute increase of traumatic cases therefore amounts to $I \cdot 7$ per cent. per annum.

Assumption I-that the number of traumatic cases is increasing-is therefore justified in Switzerland.

An incidence of about 80 traumatic cases per annum in a population of about $5 \frac{1}{2}$ million corresponds to about I5 per million. If one adds I 5 to I 8 per cent. of cases of acute non-traumatic paraplegia the total of patients requiring specialised attention in a spinal centre is not far from double the number which so far has served as a basis for planning.

Assumption 2, therefore, appears to be out of date.

This short record will, we hope, encourage the authorities of other countries to base the provision of beds in future spinal centres on similar statistical surveys.

\section{ACKNOWLEDGEMENT}

We wish to express our appreciation of the friendly, speedy and efficient help received from Professor Tanner and his company in starting this project. 